Article

\title{
Experience Sharing on Virtual COOP Training to Mechanical Engineering Students during the COVID-19 Pandemic
}

\author{
Abdul Samad Mohammed ${ }^{1,2}$ (D) \\ 1 Department of Mechanical Engineering, King Fahd University of Petroleum and Minerals, \\ Dhahran 31261, Saudi Arabia; samad@kfupm.edu.sa \\ 2 Interdisciplinary Research Center for Advanced Materials, King Fahd University of Petroleum and Minerals, \\ Dhahran 31261, Saudi Arabia
}

Citation: Mohammed, A.S. Experience Sharing on Virtual COOP Training to Mechanical Engineering Students during the COVID-19 Pandemic. Sustainability 2021, 13, 11401. https://doi.org/10.3390/ su132011401

Academic Editors: Marc Alier, María José Casañ and David Fonseca Escudero

Received: 17 September 2021

Accepted: 13 October 2021

Published: 15 October 2021

Publisher's Note: MDPI stays neutral with regard to jurisdictional claims in published maps and institutional affiliations.

Copyright: (C) 2021 by the author. Licensee MDPI, Basel, Switzerland. This article is an open access article distributed under the terms and conditions of the Creative Commons Attribution (CC BY) license (https:// creativecommons.org/licenses/by/ $4.0 /)$.
Abstract: The COVID-19 pandemic, which started in December 2019, brought about a paradigm shift in the lifestyles of people worldwide due to the imposed constraints and lockdowns aimed at containing the spread of the infection. Each and every aspect of our lifestyle such as eating, travelling, socializing and learning was affected by this pandemic. Even the education sector was not untouched due to this pandemic, which caught the various stakeholders of this industry, such as the students, faculty and the administration, unaware. The education of a complete generation of kids and adults all over the world required some drastic adjustments so that their learning process would continue unaffected. Even though distance learning and online teaching have been around for a long time in the education sector, its importance was felt during this last year because of the role it played in the transfer of knowledge to students during the lockdowns wherein the students did not have access to physical classrooms and schools. Faculty, students and the administration developed new innovative ideas to adjust to this new change in teaching/learning styles and made the transition for all stakeholders a smooth and an enlightening experience. One such change had to be made in the delivery style of the cooperative program (COOP) for Mechanical engineering students at King Fahd University of Petroleum and Minerals (KFUPM). COOP is a 9-credit hour course that a student with a junior standing in the Applied Mechanical Engineering program (AME) has to take and pass. It requires the student to spend about seven months in the industry to learn applications in a practical environment and solve practical problems with the aid of the theoretical knowledge gained by him in the courses. However, due to the sudden lockdown in March 2020, most of the industries downed their shutters, which left these poor students halfway stranded through their COOP course. Hence, in order to cater to these students, the administration came up with the idea of substituting physical training with virtual training without compromising on the quality of the education. Comprehensive procedures on the various modules designed and delivered under this new virtual training program, the mode of instruction used, the assessment methods implemented and the experiences of the students are presented in this paper, which can be of tremendous help to various stakeholders.

Keywords: online education; virtual training; higher education

\section{Introduction}

In a COOP program, which lasts for a duration of 7 months, students are supposed to be working in an industrial environment. COOP is a 9-credit hour course that a student with a junior standing in the Applied Mechanical Engineering program (AME) has to take and pass. They are provided training in the various departments under the supervision of a mentor in the industry. During this period, the students are also required to look out for some good mechanics-oriented case studies so that they can conduct a complete root cause analysis in order to understand failure modes and suggest solutions to prevent the same outcomes in the future. Moreover, the student is also required to work on one design 
case study, which should involve a good amount of design components. At the end of their 7-month period of COOP training in the industrial setup, they are required to submit a final report and to provide a presentation about their accomplishments in the ME department. However, the students who had started their COOP training in the beginning of the second semester of 2020 (January 2020) had only completed a period of 8 weeks in the physical mode when the COVID-19 pandemic struck the world.

The COVID-19 pandemic, which started in December 2019, brought about a paradigm shift in the lifestyles of the people worldwide due to the imposed constraints and lockdowns aimed at containing the spread of the infection. Each and every aspect of our lifestyle such as eating, travelling, socializing and learning was affected by this pandemic. Even the education sector was not untouched due to this pandemic, which caught the various stakeholders of this industry, such as the students, faculty and the administration, unaware. The education of a complete generation of children and adults all over the world required some drastic adjustments so that their learning process could continue unaffected. Even though distance learning and online teaching have been around for a long time in the education sector, its importance was felt during this last year because of the role it played in the transfer of knowledge to the students during the lockdowns wherein the students did not have access to the physical classrooms and schools. Faculty, students and the administration developed new innovative ideas to adjust to this new change in terms of teaching/learning styles and made the transition for all the stakeholders a smooth and an enlightening experience. One such change had to be made in the delivery style of the cooperative program (COOP) for the Mechanical engineering students at King Fahd University of Petroleum and Minerals (KFUPM). As mentioned above, it requires the student to spend about seven months in the industry to learn applications in a practical environment and solve practical problems with the aid of the theoretical knowledge gained by the student in the courses. However, due to the sudden lockdown in March 2020, most of the industries in KSA downed their shutters, which left these poor students halfway stranded in their COOP course. Although the companies had to close down due to the lockdowns, the students still continued with their COOP training in an online mode until their 18 th week.

Hence, in order to cater to these students so that they complete the total duration of the 28 weeks of their COOP training, the administration came up with the idea of substituting physical training with virtual training without compromising on the quality of the education. Comprehensive procedures on the various modules designed and delivered under this new virtual training program, the mode of instruction used, the assessment methods implemented and the experiences of the students are presented in this paper, which can be of tremendous help to the various stakeholders.

\section{The New Virtual Training Program}

A new virtual training program was designed to remedy the 10 weeks lost by students in their physical COOP training program. By this stage, the students would have already completed a period of 18 weeks but that too was stopped during the intermittent physical phases due to the administered lockdowns. Thus, they could hardly experience the chance to work on some good engineering case studies, including a design case study that was the requirement for passing a COOP course. Hence, keeping in mind all of these constraints, the new program was designed to train the students in different aspects so that they could receive holistic and comprehensive training without compromising on quality. Hence, the 10 weeks of virtual training was divided into three phases as follows:

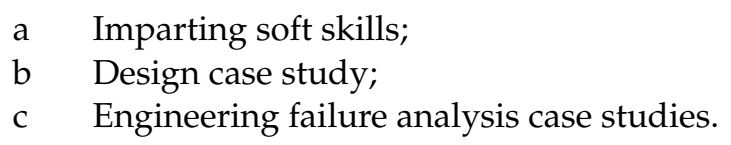

Figure 1 shows the schematic of the various skills that were planned to be imparted to the students within this virtual training program. 


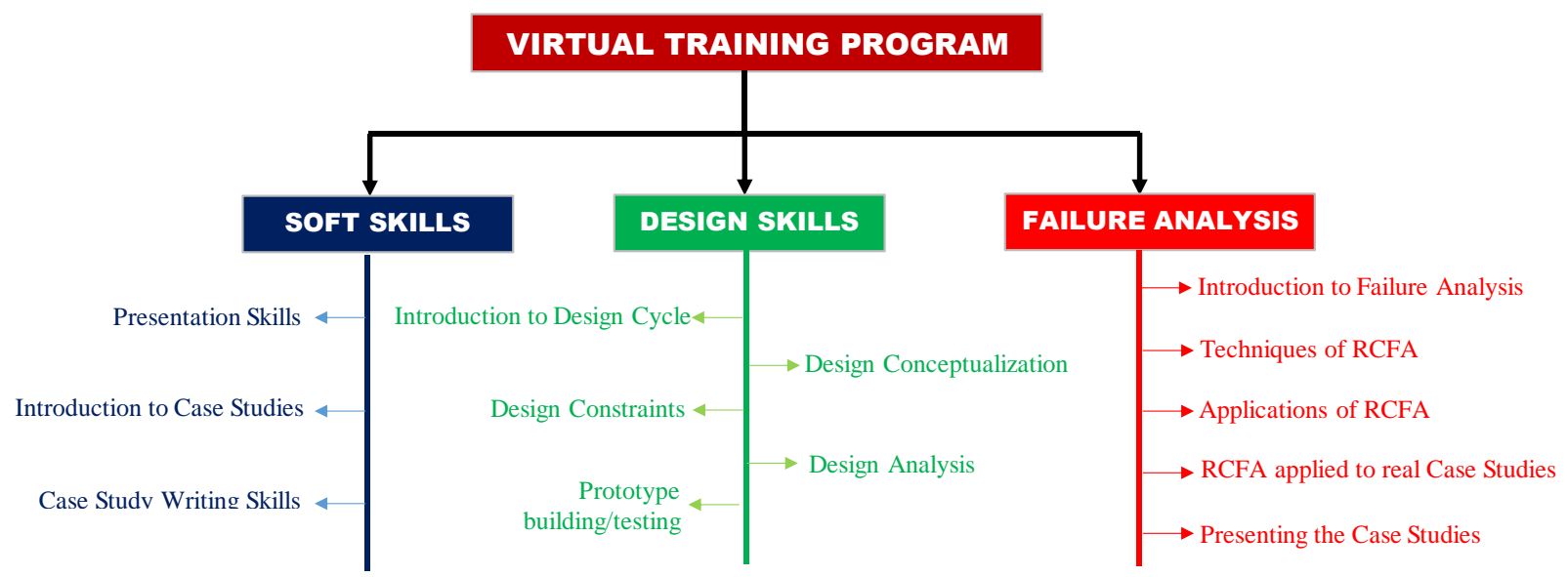

Figure 1. A bird view of the virtual training program.

\subsection{Soft Skills}

In view of the holistic development of various skills relative to a mechanical engineering student to which he is exposed to when he enters the industry for the COOP training program, the category of soft skills was included in the virtual training program. Soft skills were imparted at the instructor level during a one-to-one interaction with the students in an online class and also at the university level, which was performed through various presentations and seminars by experts in the field. At the instructor level, the first week was completely dedicated for imparting soft skills, such as making effective presentations, delivering presentations efficiently and writing engineering case studies in an effective manner. A hybrid strategy of synchronous and asynchronous learning was adopted so that the students are taught and then assessed in these skills. Table 1 presents the schedule of the first week of this hybrid strategy.

Table 1. Various topics covered along with the mode and assessment method followed during the first week of imparting soft skills to the students.

\begin{tabular}{|c|c|c|c|}
\hline Day & Mode & Topic & Assessment Method \\
\hline 1 & Synchronous-Online Lecture & Making Effective Presentation Slides & $\begin{array}{c}\text { Asynchronous-Every student makes a } \\
\text { presentation following all the guidelines } \\
\text { shown to them during the lecture and } \\
\text { submit the same for assessment. }\end{array}$ \\
\hline 2 & Synchronous-Online Lecture & Delivering Presentations Effectively & $\begin{array}{c}\text { Asynchronous-Every student delivers } \\
\text { and records his presentation that he } \\
\text { prepared in the previous step and sends } \\
\text { the youtube link for assessment. }\end{array}$ \\
\hline 3 & Synchronous-Online Lecture & $\begin{array}{c}\text { Introduction to Case Studies and a how } \\
\text { to present a case study effectively }\end{array}$ & $\begin{array}{c}\text { Asynchronous-Every student selects a } \\
\text { case study, categorizes it, writes a report } \\
\text { following the guidelines shown to him, } \\
\text { and submits it for assessment. }\end{array}$ \\
\hline
\end{tabular}

\section{Presentation Skills}

Making good presentations in addition to delivering them in a professional and an effective manner is one of the most important silks required by an engineering student when he ventures into the industrial world. Even though the students are required to make and deliver numerous presentations for their course projects, they have never been given formal training at any level of their studies. Hence, introducing this component in the first week was very effective, as gauged by the responses of the students.

The first lecture was dedicated to training students in making good presentations. Guidelines to be followed during the making of the presentation in terms of the selection of 
slides color, scheme, fonts and font size were shown. Arrangements of the slides focusing on a few mandatory slides such as the title slide, presentation outline slide and the conclusion slide and rules to be followed for bulleting and numerical lists were presented. The amount of content on each slide and the most important components of a good presentation such as introduction, methodology, results/discussion and bibliography were discussed with the students. Based on the guidelines shown in this lecture, the students were required to make a 10 min presentation including all the important components on any engineering topic of their interest and to submit the presentation for assessment. Students selected varied interesting topics, did a good amount of research and prepared the presentations.

It was made clear to the students that making an effective presentation is just the half work completed because the second half, which is more challenging, is to deliver the presentation in an effective manner so that the intended message is conveyed to the targeted audience. Hence, the focus of the second lecture was to teach the students how to deliver their presentations effectively. Questions such as how to get dressed, how to practice, how to maintain eye contact with the audience, how to answer questions, how to show confidence, how to maintain correct body posture, etc., were addressed and discussed elaborately. The students were required to deliver and record their presentations, which they had prepared in the first assignment, and to upload them on YouTube so that they can be assessed and proper feedback can be provided for further improvement.

The third component that the students were taught under the soft skills category was the case studies. It is very important for a mechanical engineering student to differentiate between different types of case studies, categorize them and present them in a professional manner. It is worthy for a mechanical engineering student to have this skill in his toolkit before he ventures out into the industry. Hence, in this lecture, students were exposed to different types of case studies (historical, design and real) and the guidelines to identify them. Procedures to identify, write and present a case study in an effective manner were discussed. Students were required to select a case study and submit a short report following all the guidelines in order to be assessed and to receive timely feedback.

\subsection{Design Skills}

One of the most important components of a physical COOP training for the students was to identify, work and present a case study with a substantial design involved. Hence, this component was included in the virtual training program so that the students can be exposed to a comprehensive design process and work on a case study involving a good amount of design skills. The objective of this module was to impart the skills needed to design a product from conceptualization to prototype building, even during these challenging times. In online environment, students miss the ability to communicate their thoughts with different kinds of audiences. However, these skills are developed quite naturally when the students attend physical training in industries as they have to communicate with different people such as higher management, their colleagues/peers or technicians/engineers. Hence, to overcome this challenge, it was decided that the students would work in teams with a team leader who would be changed on a regular basis. Table 2 shows the different modules and modes of delivery that were undertaken during online teaching of the design skills component.

\subsubsection{Introduction to the Design Process and Formation of Teams}

In this online lecture, the students were introduced to the complete design process as shown in Figure 2. The teams were formed, and a leader for each team was appointed with their specific duties listed out. Students were shown the importance of communication among themselves if they wanted to successfully design a product. The theme given to the students for designing was based upon the COVID-19, and they were asked to come up with some creative ideas of designing a product that would help in curbing the spread of COVID-19. Each team would be presenting two to three initial ideas, and then the best design would be selected based upon a feasibility study. 
Table 2. Different modules covered in the Design Skills component of the virtual training program.

\begin{tabular}{|c|c|c|c|}
\hline Week & Mode & Topic & Assessment Method \\
\hline \multirow[b]{2}{*}{1} & Synchronous-Online Lecture & $\begin{array}{c}\text { Introduction to the Design } \\
\text { Process and formation of teams }\end{array}$ & N/A \\
\hline & Synchronous-Online Session & $\begin{array}{l}\text { Brainstorming of different ideas } \\
\text { to design a product for preventing } \\
\text { the spread of COVID-19 }\end{array}$ & $\begin{array}{c}\text { Asynchronous-Every team researches, } \\
\text { brainstorms and presents atleast two to three } \\
\text { ideas of product designs to prevent the spread } \\
\text { of COVID-19. }\end{array}$ \\
\hline \multirow{2}{*}{2} & Synchronous-Online Session & $\begin{array}{l}\text { A feasibility study of the } \\
\text { selected idea/product }\end{array}$ & $\begin{array}{l}\text { Asynchronous-Every team, presents the } \\
\text { feasibility study of the selected project in } \\
\text { terms of design, cost and fabrication }\end{array}$ \\
\hline & Synchronous-Online Lecture & $\begin{array}{l}\text { Guidelines to write a } \\
\text { design proposal }\end{array}$ & $\begin{array}{l}\text { Asynchronous-Every team submits a } \\
\text { comprehensive proposal for designing and } \\
\text { fabricating the selected product. }\end{array}$ \\
\hline 3 & Synchronous-Online Session & $\begin{array}{l}\text { Design analysis of the } \\
\text { proposed idea/product }\end{array}$ & $\begin{array}{l}\text { Asynchronous-Every team conducts a } \\
\text { comprehensive design analysis on the } \\
\text { proposed idea/project and comes up with a } \\
\text { final design for the product. }\end{array}$ \\
\hline \multirow[t]{2}{*}{4} & Synchronous-Online Session & $\begin{array}{l}\text { Prototype development / } \\
\text { Final presentation }\end{array}$ & $\begin{array}{l}\text { Asynchronous-Every team develops a } \\
\text { "dirty" working prototype of the product and } \\
\text { make a final presentation to the whole class. }\end{array}$ \\
\hline & \multicolumn{3}{|c|}{ Final Report Submission } \\
\hline
\end{tabular}

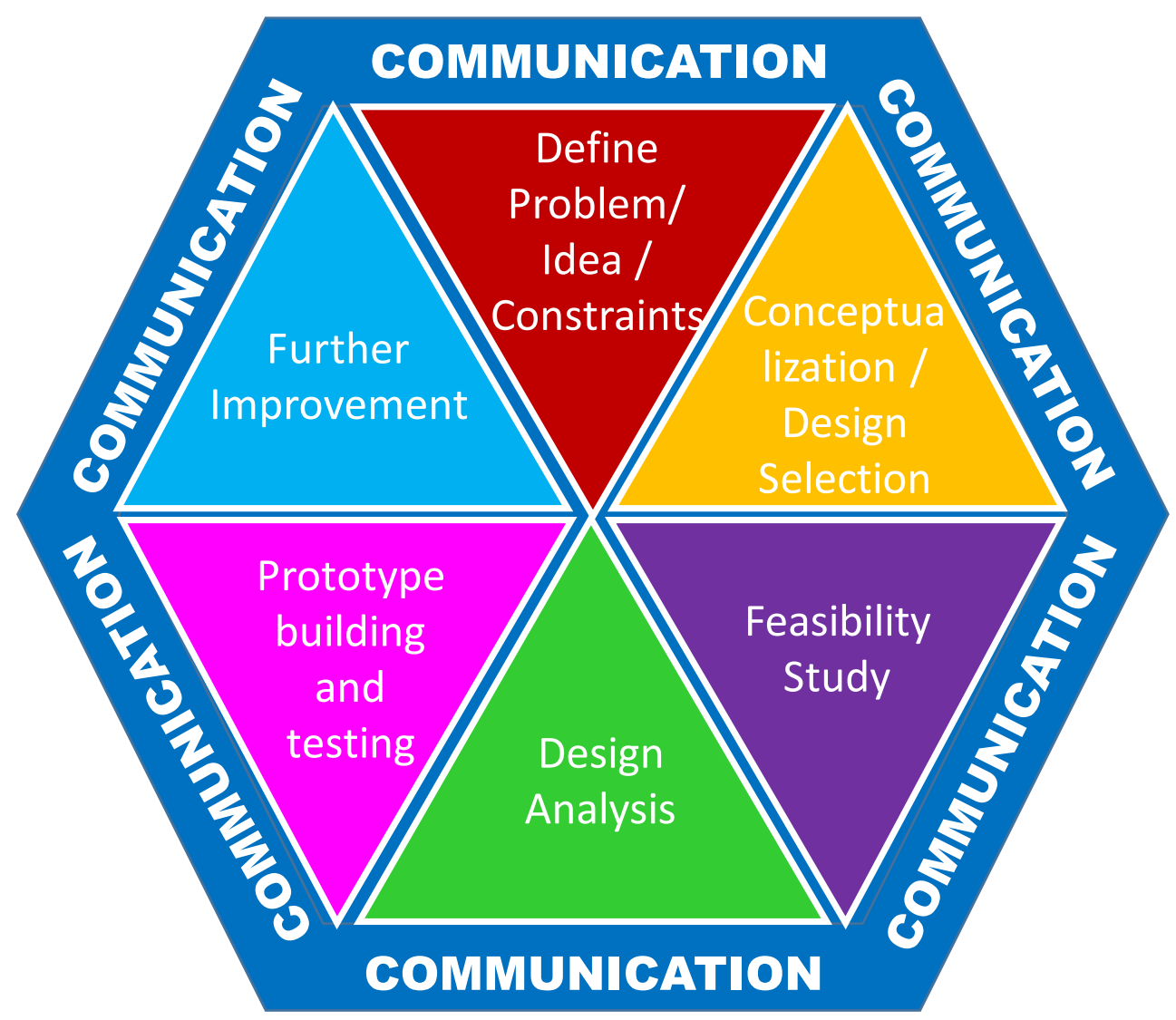

Figure 2. A schematic showing the different stages of a design process.

Figure 3 shows the tasks assigned to the teams at the end of this lecture. The title of the project was given as, "Design of a product/machine in prevention the spread of COVID-19". 

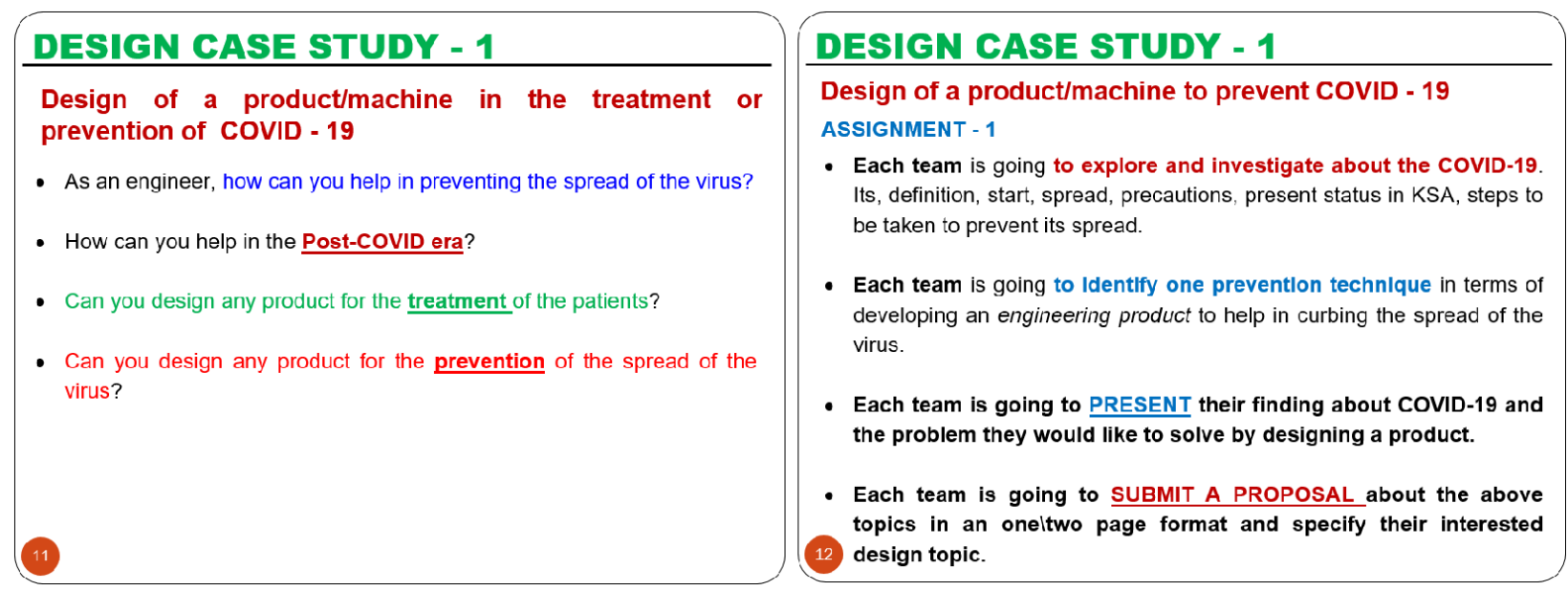

Figure 3. Details of assignment-1 given to the students.

\subsubsection{Brainstorming and Narrowing down on One Product Design}

Different teams proposed a set of ideas, such as the design of contactless elevator buttons, the design of gloves with sensors, the design of contactless opening of the doors, the design of contactless sanitizer dispensing machines, etc. However, after thorough brainstorming and after conducting a feasibility study, which included the constraint of building a prototype with COVID-19 restrictions, the teams proposed the following ideas, as shown in Table 3, and submitted a well written proposal by following all the guidelines shown to them.

Table 3. Titles of the design projects that the student selected for the design case study.

\begin{tabular}{cc}
\hline Team \# & Title of the Design Idea/Project \\
\hline 1 & Design of Self-Sanitizing Wheel Button \\
\hline 2 & Foot operated sanitizer stand \\
\hline 3 & Free-Hand Door Opener \\
\hline 4 & Sterilization Box \\
\hline 5 & Design of a Foot operated sanitizer stand \\
\hline
\end{tabular}

\subsubsection{Design Analysis and Prototype Development}

Every team conducted a thorough feasibility study for their suggested projects and justified their creative ideas in terms of functionality, ease of design and manufacturability and cost. They conducted a good design analysis by using SolidWorks and cosmos in order to provide shape and dimensions to their ideas. Ultimately, each of the teams developed their respective prototypes by using raw materials found in their homes and presented their final presentations. Figure 4 shows the conceptualized and the developed prototypes by the various teams.

\subsubsection{Summary}

Throughout the design process, the teams engaged in effective communication and discussion about the various aspects of their ideas in order to make sure that their idea is realized into a working prototype. The highlight of the developed prototypes is that all of them were built within the confines of their homes by using scrap material at their disposal, adding another dimension to their creative efforts and ideas. All the projects focused on the idea of preventing the spread of COVID-19, which not only helped the teams in realizing their creativity but also helped them in increasing their knowhow about this dangerous virus during their extensive research on the topic. Within the module of design skills, the teams practiced writing effective proposals by pondering the following 
four questions: Scope — what do you intend to design; Significance-why do you intend to design; Methodology — how do you intend to design; Timeline - when do you intend to finish the design? The students learnt about the procedures for conducting feasibility studies of their design in terms of cost, functionality, ease of manufacturing and overall usage relative to the community.

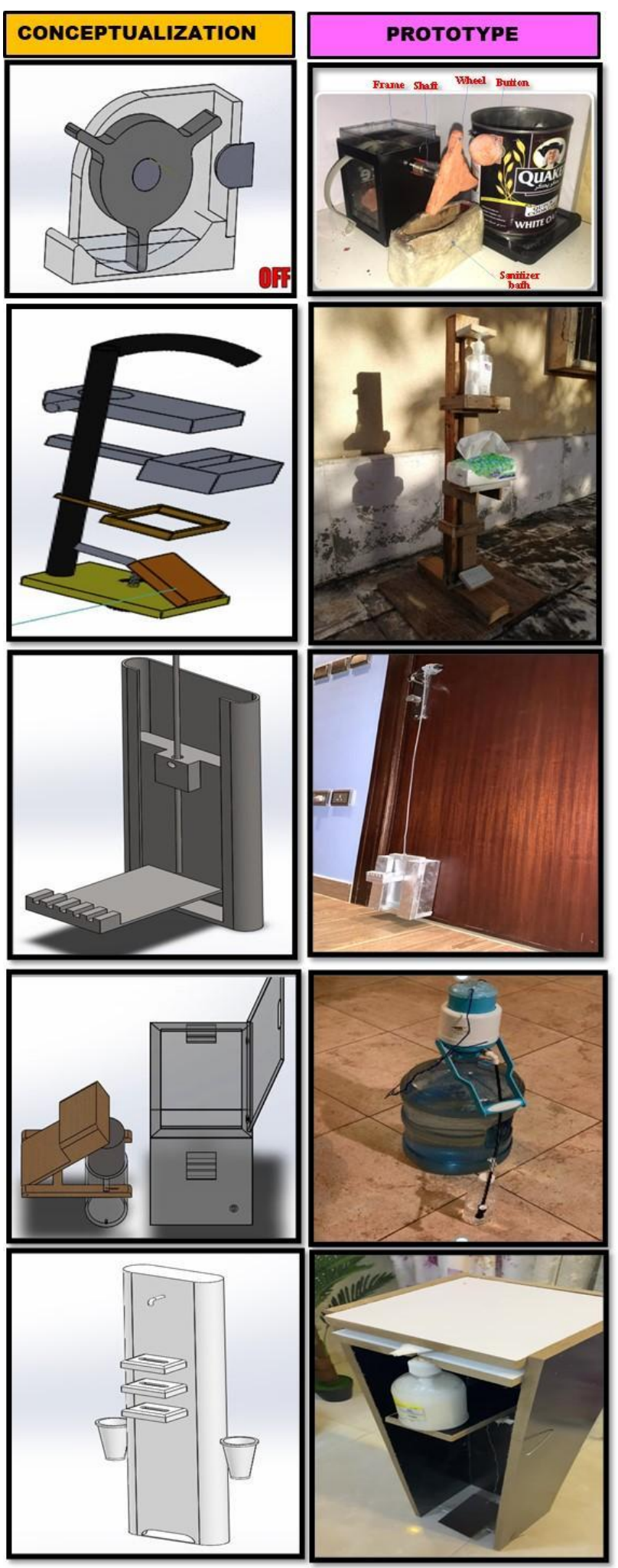

Figure 4. Conceptualized and developed prototypes by the various teams. 


\subsection{Failure Analysis}

The failure analysis module was included in the virtual training program in order to equip students with this very important tool, which will help them in conducting engineering failure analysis of components in their careers in different industries. Case studies on failure analysis are included as one of the major components of physical COOP training wherein the students are required to work on at least two engineering case studies and present a complete analysis of the same. However, to compensate for this missed opportunity due to the COVID-19 situation, the failure analysis module was designed for the students in the virtual training program. Table 4 shows the various topics included within this module. As observed from Table 4 and Figure 5, the topics covered within this module focused mainly on equipping students with this very important tool of guidelines and procedures to be followed for conducting effective failure analyses.

Table 4. Comprehensive topics covered within the Failure analysis module.

\begin{tabular}{|c|c|c|c|}
\hline Week & Mode & Topic & Assessment Method \\
\hline 1 & Synchronous-Online Lecture & Basics of Failure Analysis & $\begin{array}{l}\text { Asynchronous-Every team conducts an extensive } \\
\text { literature review on any one assigned industry to find } \\
\text { out the most common failures in the } \\
\text { equipment/machinery within that industry. }\end{array}$ \\
\hline 2 & Synchronous-Online Session & $\begin{array}{l}\text { General Procedure for } \\
\text { Failure Analysis }\end{array}$ & $\begin{array}{l}\text { Asynchronous-Every team will research on one step } \\
\text { of the failure analysis procedure and present to the } \\
\text { class all the different tools that are used. }\end{array}$ \\
\hline 3 & Synchronous-Online Session & $\begin{array}{l}\text { Root Cause Failure } \\
\text { Analysis (RCFA) }\end{array}$ & $\begin{array}{l}\text { Asynchronous-Each team will conduct an extensive } \\
\text { literature review on one of the assigned RCFA } \\
\text { technique and make a comprehensive presentation to } \\
\text { the class. }\end{array}$ \\
\hline $4 \& 5$ & \multicolumn{3}{|c|}{$\begin{array}{c}\text { Final Assignment: Each team is supposed to select one mechanical component from the common list of } \\
\text { components/equipment that they come across in their selected industry in Assignment- } 1 \text { and present a comprehensive } \\
\text { research on the different failure modes of these components. They will also select two industrial case studies and present } \\
\text { them elaborately in the class after getting an approval from the instructor. }\end{array}$} \\
\hline & \multicolumn{3}{|c|}{ Final Report Submission } \\
\hline
\end{tabular}

\subsubsection{Basics of Failure Analysis}

Students were taught the basics of failure analysis by showing them different examples of failures and explaining the different types of failures such as ductile, brittle, fatigue, high temperature, etc. The most common causes of failures were also discussed along with the different modes of failures they can encounter in real industrial setups. The topic also covered the most important traits, such as unbiasedness, patience, communication skills, understanding about a topic, etc., that are required in a good failure analyst.

\subsubsection{General Procedure of Failure Analysis}

Students were taught about the steps that are followed for conducting effective failure analyses, such as the following:

- Collecting background information;

- Preliminary examination;

- Selection, preservation and cleaning of the sample;

- Destructive and non-destructive testing;

- Metallographic examination;

- Establishing the fracture mechanisms;

- Analysis of findings of investigation;

- Report writing with recommendation. 

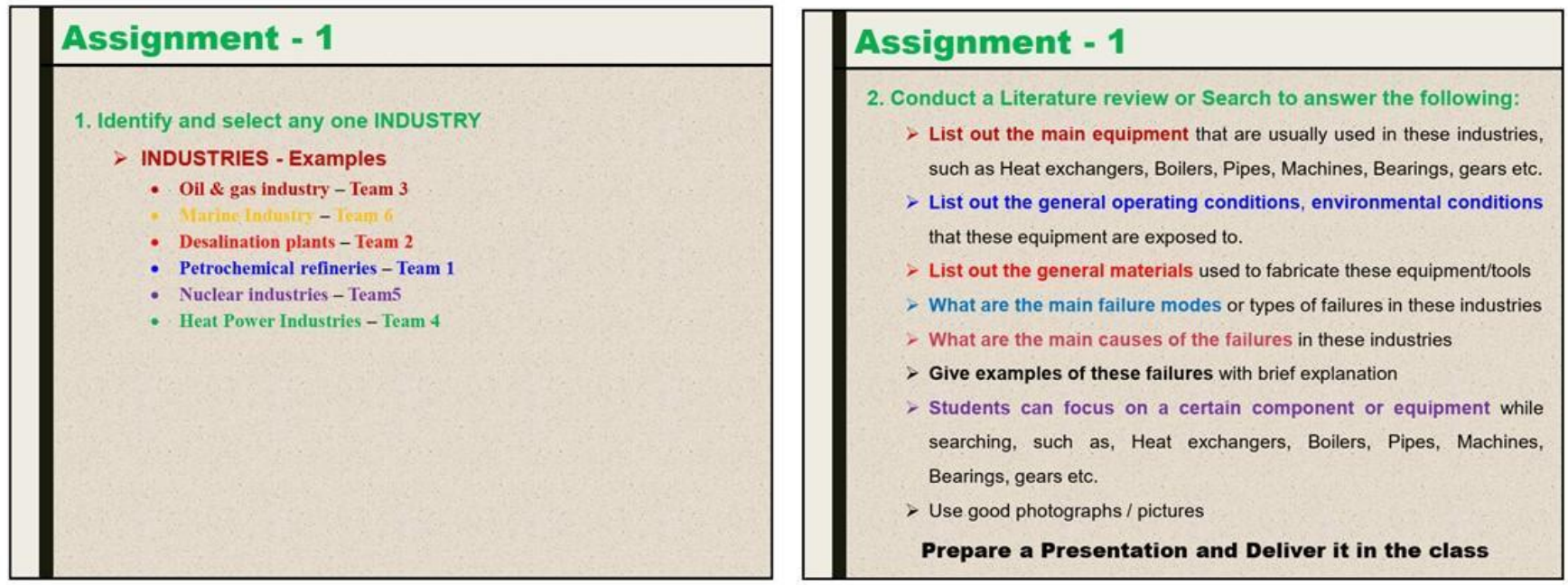

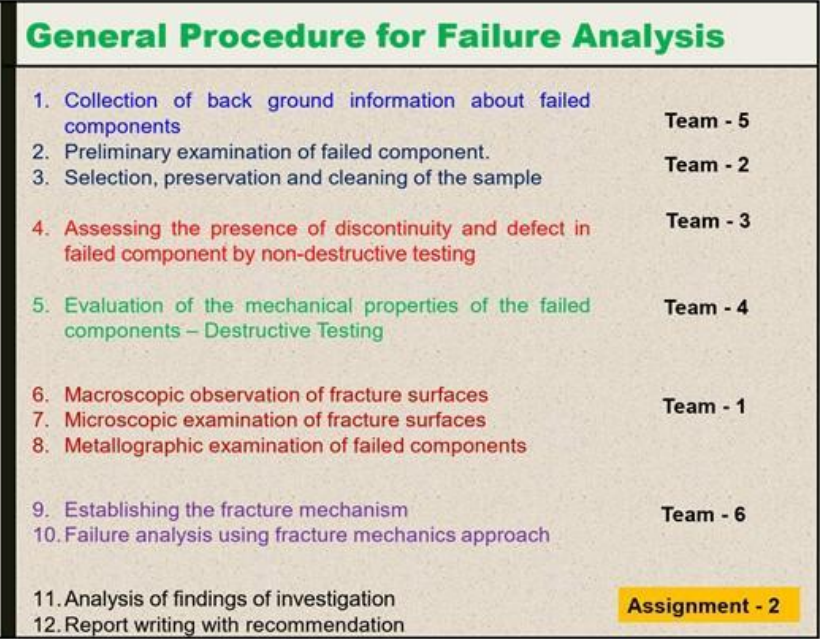

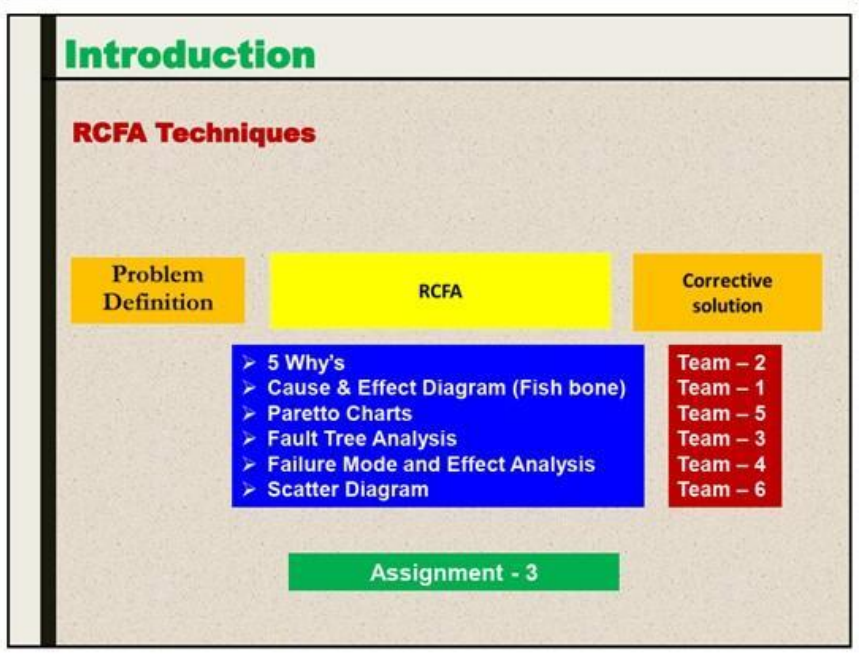

\section{Assignment - 4}

Failure Analysis of a Mechanical Component

\section{PART - 1}

Students are supposed to do a thorough review to answer the following:

\section{Introduction:}

Function of the selected component, its usage in various parts, its purpose, its function etc. Structure/parts of the selected component and their function. Materials used for the different parts of the selected component.

Types of loads/stresses acting in the selected component

Causes of failure of the selected component

How to prevent the failures in the selected component
PART - 2

- Students are supposed to search for two case studies on the failure of the step-by-step procedure to find out the root cause of the failure.

- It is advisable to apply any one of the RCFA techniques to the case studies, even if the original case study does not do that.

- Students are supposed to follow all the principles of failure analysis that were listed out in the previous assignments as closely as possible while presenting the case studies.

- The case studies presented should be very comprehensive with all details.

\section{Assignment - 4}

Failure Analysis of a Mechanical Component

\begin{tabular}{|l|c|c|}
\hline \multicolumn{1}{|c|}{ Component } & Team & Presentation Date \\
\hline Bearings & $\mathbf{1}$ & Thursday \\
\hline Pumps & $\mathbf{2}$ & Thursday \\
\hline Boilers & $\mathbf{3}$ & Tuesday \\
\hline Heat exchangers & $\mathbf{4}$ & Wednesday \\
\hline Pressure vessels & $\mathbf{5}$ & Wednesday \\
\hline Turbines & $\mathbf{6}$ & Tuesday \\
\hline
\end{tabular}

\section{To be Submitted:}

- Each team will be presenting the Part-1 and Part-2 of Assignment 4 in the class on the scheduled date and time and submit the slides on Black Board.

Figure 5. List of assignments given to the students within the failure analysis module.

\subsubsection{Root Cause Failure Analysis Techniques}

Student were introduced to two methods for approaching failures. One is Reactive Management. The other is the Proactive Management. Reactive management refers to quickly reacting in order to solve the problem by treating its symptoms, while proactive management tends to treat the root cause of the problem by using well-established techniques 
(RCFA Techniques), which assist in determining the root cause. The different techniques that were introduced to the students included the following:

- $\quad$ The five WHYs technique;

- Fishbone Technique;

- Pareto Chart;

- Fault-Tree-Analysis;

- Failure Mode and Effect Analysis;

- Scatter Diagram.

\subsubsection{Final Assignment}

As observed from Figure 5, the students were assigned a comprehensive final assignment wherein they had to apply all the theoretical knowledge they had gained during the previous lectures in order to solve real failures in machines and components. Each team was assigned a certain component/equipment on which they were supposed to conduct an extensive literature review and explain to the class the most common modes of failures in those components and how to prevent them. Each team also had to select at least two real case studies from the literature and present the RCFA to the class along with a final report.

As observed from Table 5, the teams performed a thorough review about the different components assigned to them in order to present the various types of the common failures encountered by each one of them. Moreover, they selected some very interesting case studies in order to present them comprehensively to the class.

Table 5. Different case studies analyzed and presented by the students as their final assignments.

\begin{tabular}{|c|c|cl|}
\hline Team \# & Component & \multicolumn{1}{|c|}{ Case Studies } \\
\hline $\mathbf{1}$ & Bearings & $\begin{array}{l}\text { - } \\
\text { - }\end{array}$ & $\begin{array}{l}\text { An Air Crash Due to Fatigue Failure of a Ball Bearing } \\
\text { Diesel Engine Crankshaft Journal Bearing Failure }\end{array}$ \\
\hline $\mathbf{2}$ & Pumps & $\begin{array}{l}\text { - } \\
\text { - }\end{array}$ & $\begin{array}{l}\text { Pump impeller failure } \\
\text { Pump shaft failures }\end{array}$ \\
\hline $\mathbf{3}$ & Boilers & $\begin{array}{l}\text { - } \\
\text { - }\end{array}$ & $\begin{array}{l}\text { Failure Investigation of A High-Pressure Shell Boiler } \\
\text { Failure analysis of furnace shell plate }\end{array}$ \\
\hline $\mathbf{5}$ & Pressure Vessels & $\begin{array}{l}\text { - } \\
\text { - }\end{array}$ & $\begin{array}{l}\text { Corrosion failure of a tube heat exchanger } \\
\text { Failure analysis of tube-to-tube sheet welded joints in a } \\
\text { shell-tube heat exchanger }\end{array}$ \\
\hline $\mathbf{6}$ & Turbines & $\begin{array}{l}\text { Vessel containing a pressurized fluid failed by the } \\
\text { phenomenon of external-pressure buckling. } \\
\text { Polyethylene Wax Processing Facility Explosion and Fire }\end{array}$ \\
\hline
\end{tabular}

\subsubsection{Summary}

The module equipped trainees with failure analysis general procedures and root cause failure analysis skills. In addition, the module explored failures in many mechanical equipment/components (e.g., pumps, turbines and bearings) in different industries (including oil and gas, petrochemical refining and others). Students used the general failure analysis procedure to analyze a failed component. The students were then introduced to two methods for approaching failures. One is Reactive Management. The other is Proactive Management. Reactive management includes quickly reacting in order to solve the problem by treating its symptoms, while proactive management tends to treat the root cause of the problem by using well-established techniques (RCFA Techniques) that assist in determining 
the root cause. The students practiced all the RCFA techniques, including the five WHYs technique, Fishbone Technique, Pareto Chart, Fault-Tree-Analysis, Failure Mode and Effect Analysis and Scatter Diagram.

\section{Testimonials of the Students}

The following is the testimonial of a student who had attended the virtual training program with respect to its effectiveness and the disadvantages as compared to physical training, "Despite the challenges of virtual training (VT), the combination of physical training (PT) and VT formed one unique experience. If we focus on VT alone, VT was one successful experience. It may not substitute PT at the moment, but it can complement it though (Table 6). In my opinion, despite the fact that VT will never match PT, it has great potential of evolving over time in a completely different track. We might see the implementations of several technologies (Such as Graphics, artificial intelligence (AI), virtual reality (VR), Internet of things (IoT), and others) to bring VT to a different level that has never been reached by PT. The comparison between the VT and the PT programs, maybe linked to Video Games vs. Traditional Games comparison. Video games are now considered the most favorable way of gaming. Collaboration with video games developers/designers to improve virtual learning experience is the ideal development track to follow".

However, a short survey was also conducted at the end of the VT program among the students by posing the following questions and the responses of the students as presented in Table 7:

Q1. Give your comments about the Soft Skill sessions conducted in the initial part of the VT;

Q2. Give your comments about the Experimental Design Case Study conducted in the second part of the VT;

Q3. Give your comments about the Failure Analysis Sessions conducted in the last part of the VT;

Q4. How was your VT experience in comparison to the physical training in the company?

Table 6. Comparison of physical and virtual training environments as presented by the students.

\begin{tabular}{|c|c|c|c|}
\hline & PT & $\begin{array}{l}\text { VT } \\
\end{array}$ & \\
\hline $\begin{array}{l}\text { Communication/Accessibility/ } \\
\text { Monitoring }\end{array}$ & 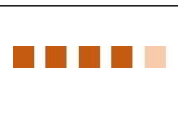 & 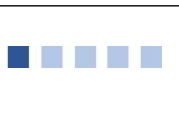 & $\begin{array}{l}\text { I strongly recommend collaborating with video games } \\
\text { community as they have proven their success in designing } \\
\text { operating, and maintaining effective communication platforms }\end{array}$ \\
\hline Visuals/Sensing/Observing & 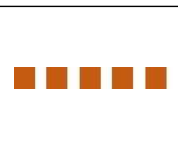 & 口ם⿴囗十 & $\begin{array}{l}\text { I strongly recommend injecting more visual aids to maximize } \\
\text { the simulation of physical training. Again, if we could only } \\
\text { collaborate with video games graphic designers, we can bring } \\
\text { VT to a completely different level }\end{array}$ \\
\hline Safety/Health/Environment & 口ロ⿴囗十 & 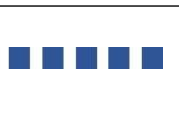 & $\begin{array}{l}\text { VT provides much safer work/learning environment for } \\
\text { trainees against risks and hazards, especially if } \mathrm{PT} \text { is in } \\
\text { factories, plants ... etc }\end{array}$ \\
\hline Transportation & 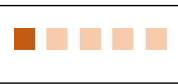 & $\square \square \square \square \square$ & $\begin{array}{l}\text { Traffic jams, and car parking are some examples of } \\
\text { transportation issues that were eliminated by VT }\end{array}$ \\
\hline Accommodation & 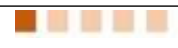 & 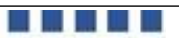 & Accommodation issues were also eliminated by VT \\
\hline Working hours & 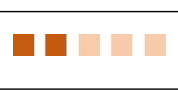 & 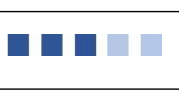 & $\begin{array}{l}\text { In VT we have demonstrated higher efficiency, that is, less time, } \\
\text { and more work }\end{array}$ \\
\hline Overall & 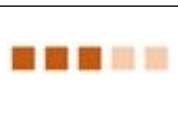 & 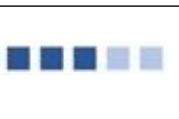 & $\begin{array}{l}\text { Currently, I strongly recommend combining PT with VT for all } \\
\text { UG students as they are complementing each other. VT should } \\
\text { be a pre-requisite to PT }\end{array}$ \\
\hline
\end{tabular}


Table 7. Summary of the responses received by 9 students with respect to their impression about the VT Program.

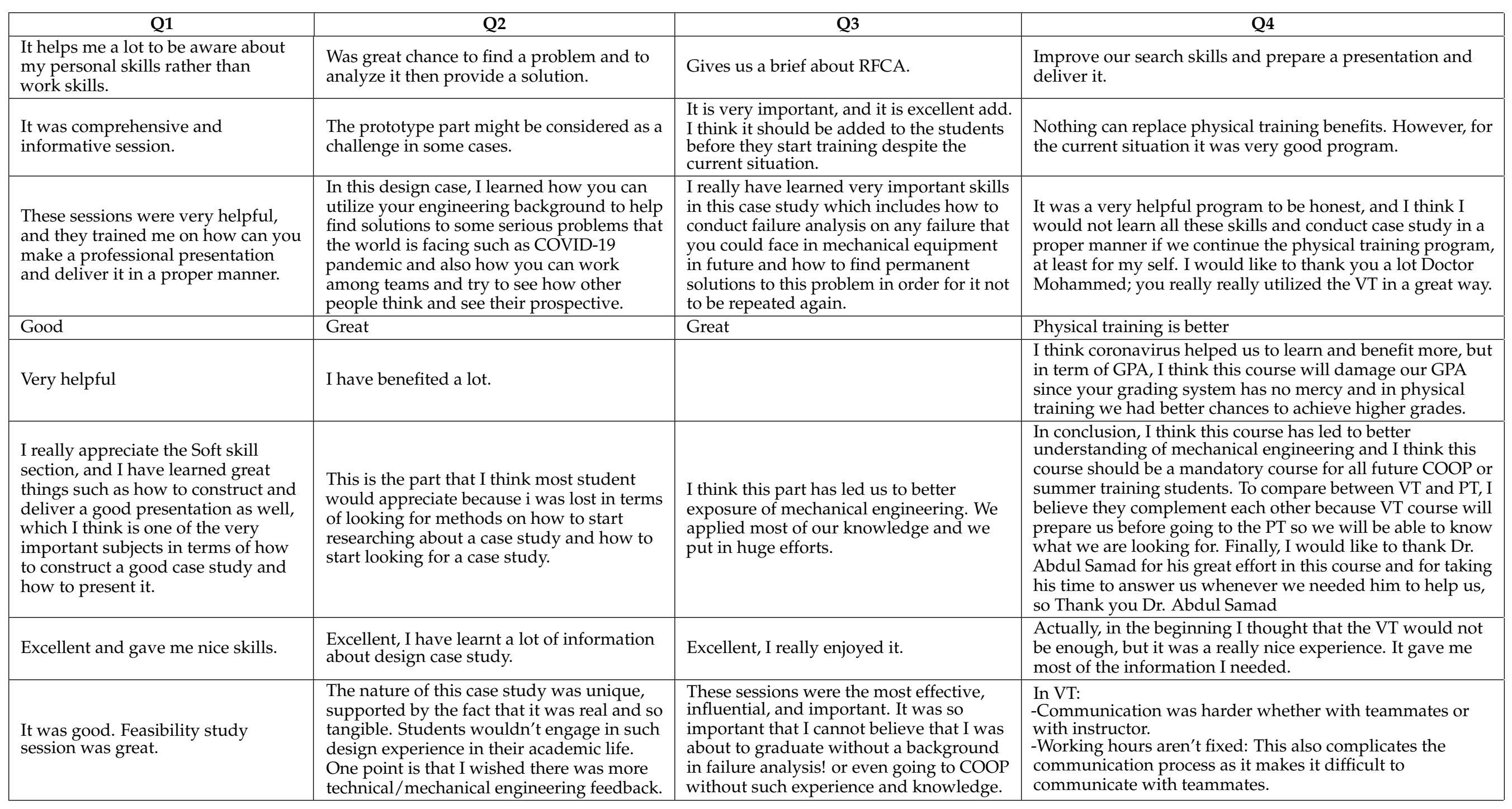


As observed from the students' responses, the VT program in general turned out be a very effective alternative program in igniting the student's interest and motivating them to learn the different soft/design/technical skills during the pandemic. The results of the student responses can be briefly summarized as follows with respect to the various modules conducted during the VT.

\subsection{Soft Skills Module}

It can be concluded that the objectives of this module were very well achieved going by the students' responses and the assessment methods implemented in this module. All the students were very appreciative of this module as it helped them to develop much needed presentation skills and skills in terms of writing and presenting a case study. The soft skills module set the stage for the VT program as the students needed to use the skills they learnt in this module in the subsequent two modules of design and failure analysis. The success of the soft skills module was very well reflected in their presentations and case study analysis. Based on the comments from the students, this module seems be to be very important and, hence, can be made mandatory for students undertaking a COOP training program irrespective of the environment (VT or PT) in which it is conducted.

\subsection{Design Case Study Module}

Students perceived the design case study module very positively as they were extremely appreciative of the techniques they learnt in this module. As put forth by one of the students, they experienced very few chances in terms of showcasing their engineering creativity during their academic life, and this module helped them to learn and put to test their capabilities in designing and developing a product, which would help in solving real life problems and make the life of the community safer and comfortable. The various working prototypes developed by the students as solutions to maintaining hygiene during the COVID-19 pandemic as a part of this module are testimonials to the grand success of this module.

\subsection{Failure Analysis Module}

This module was also well received by the students and much appreciated. As suggested by one of the students, this module can be made mandatory for all the mechanical engineering students even if they are undertaking the COOP PT program, as this would equip them with some good technical/engineering skills in terms of conducting thorough failure analysis of mechanical components in the industrial environment. The variety of case studies researched and presented by the students on the failure analysis of different mechanical components highlights the success of this module in terms of achieving its objectives.

\subsection{Overall VT Program as Compared to the PT Program}

The students in general provided some very positive comments about the VT program, which shows its acceptance by the student community. Even though the students were of the opinion that the PT program has its own charm in terms of hands-on-experience, all of them agreed with the effectiveness of the VT program in terms of delivering the much needed skillset to the students before they venture into the PT program in the industries. As suggested by one of the students, the VT program in its current form can complement the PT program, and they may be excellent tools when taken together in terms of honing the skills of the students prior to entering the industry.

As highlighted by the students, the VT program has its own advantages such as learning important skills in the comfort of their homes under the skillful guidance of an expert at their own pace, without worrying about driving, accommodation and parking issues (to name a few). Furthermore, according to the students, the VT program provided a very safe environment than compared to the PT without compromising on the quality of training and learning. 
However, most of the students have stressed on the point that the VT program as a standalone training program may have to evolve over a period of time to incorporate the various elements of PT in different formats. Various methods have to be devised to overcome this very important challenge. The incorporation of captivating visual aids, animations or interactive lab sessions would help in making the VT sessions more intriguing and interesting. Increased collaborations with the gaming community and graphic designers/developers and the use of advanced tools such as machine learning/artificial intelligence can further help in overcoming these challenges. These steps may definitely help in implementing the VT program as a standalone module in teaching engineering students. However, in its current form, it may be an excellent supporting module for the students to equip themselves with some excellent skills before venturing out into the PT program in the industry.

\section{Lessons Learnt}

Thus, the one question that pops out of this entire exercise is "Can the VT program sustain itself as a standalone training program for engineering students?" A simple answer to this question is "Yes, it can, given that it is designed efficiently".

However, at the outset, it is accepted that online teaching/virtual training has its own advantages and disadvantages and understanding these can help all stakeholders in developing efficient strategies, resulting in effective delivery and a smooth learning experience [1-9].

\subsection{Advantages/Limitations of the Online VT Program}

- One of the major advantages of online teaching is the numerous resources other than traditional textbook materials that are at the disposal of the teachers, which helps them in delivering the lectures efficiently to the students [3]. With the advent of technology such as augmented reality [10], virtual reality [11] and artificial intelligence [12], the opportunities of developing resources for effective virtual training are numerous. It is important to develop these resources in order to engage students effectively and to impart the necessary training in such trying times.

- The other advantage that was realized by the virtual training program is the flexibility of the students to learn things at their own pace at any place and any time. Moreover, online teaching suits a variety of learning styles, giving options to students with varying intellect to learn in a conducive atmosphere. However, virtual training comes with its own set of challenges such as sense of isolation felt by the students and the instructors alike, lack of continuous focus on the screen, lack of teacher training to handle unprecedented situations and, most importantly, technological issues, which demands very robust background support [13-17].

\subsection{Recommendations}

There is a paradigm shift from teacher-centered to student-centered activities during the twenty-first century, and if we plan to experience the same shift, then the knowledge, construction and skills gained needs to happen for the learners and by the learners themselves. To assure the users and future users a means through which hybrid learning practices and applications are sustained for long-term educational impact across time, an appropriate plan for the management of hybrid learning practices is needed [18-20]. In engineering education, many authors have shown that the appropriation of scientific practices is a sophisticated, cognitive and metacognitive process that demands practice and a certain level of scaffolding [13-20].

Hence, virtual training can be effective if used in tandem physical training and not as a standalone module in the current form, as stated by many students. However, if used effectively as a supplementary module along with the physical training module, it may be an effective tool for the students to learn in a conducive atmosphere during such challenging times. 
A hybrid model wherein it is a blend of physical and a virtual training would be very helpful for the students to grasp the fundamentals of engineering easily. Virtual training shall include online synchronous learning sessions, which require real time relationships between the learners and the instructor wherein the learners are constantly being challenged with different engaging and dynamic tasks, more collaboration and open discussions. It should also include asynchronously developed content and tasks as well as online sessions, which are synchronously used to blend and adapt. It is about the knowledge and skills transferred to the students and not about the technology used.

\section{Conclusions}

As the saying goes, "Unprecedented situations demand unprecedented solutions". The COVID-19 pandemic caught the entire world unaware, with huge impacts on every walk of life. Although online teaching/learning has been in existence for a long time, the COVID-19 pandemic brought the advantages and disadvantages of this system into the open. University administrations, teaching faculty and students who once kept online teaching at bay had to resort to this model during this unprecedented situation. The versatility and flexibility of the online teaching model along with its limitations were completely exposed during these challenging times. Similarly to many educationalists all around the world, we at KFUPM also adopted this versatile teaching model in delivering virtual training to students during lockdown times. The overall experiences by the university administration, faculty and the students alike were excellent and productive during the virtual training program. However, as the students have rightly pointed out, VT can never replace PT, but it can help in enhancing the learning of the students if it is combined or made a prerequisite for PT. Moreover, the complete VT experience can be enhanced by the usage of evolving technologies such as the virtual reality, artificial intelligence, etc., to name a few.

Funding: This research received no external funding.

Data Availability Statement: None.

Acknowledgments: The author would like to acknowledge the support provided by King Fahd University of Petroleum and Minerals.

Conflicts of Interest: The author declares no conflict of interest.

\section{References}

1. Fedynich, L.V. Teaching beyond the classroom walls: The pros and cons of cyber learning. J. Instr. Pedagog. 2014, 13, 1.

2. Hrastinski, S. Asynchronous and synchronous e-learning. Educ. Q. 2008, 31, 51-55.

3. Aronoff, S.C.; Evans, B.; Fleece, D.; Lyons, P.; Kaplan, L.; Rojas, R. Integrating evidence based medicine into undergraduate medical education: Combining online instruction with clinical clerkships. Teach. Learn. Med. 2010, 22, 219-223. [CrossRef] [PubMed]

4. Middleton, A.J. How effective is distance education? Int. J. Instr Media 1997, 24, 133-138. Available online: https:/ / eric.ed.gov/ ?id=EJ569045 (accessed on 5 October 2021).

5. Tanveer, M.; Bhaumik, A.; Hassan, S.; Haq, I.U. Covid-19 pandemic, outbreak educational sector and students online learning in Saudi Arabia. J. Entrep. Educ. 2020, 23, 1-14.

6. Kerry, T.; Farrow, J. Changes in initial teacher training: Students' perceptions of the effectiveness of school-based mentoring over time. Educ. Stud. 1996, 22, 99-110. [CrossRef]

7. Konca, A.S.; Ozel, E.; Zelyurt, H. Attitudes of preschool teachers towards using information and communication technologies (ICT). Int. J. Res. Educ. Sci. 2016, 2, 10-15. [CrossRef]

8. Singh, V.; Thurman, A. How many ways can we define online learning? A systematic literature review of definitions of online learning (1988-2018). Am. J. Distance Educ. 2019, 33, 289-306. [CrossRef]

9. Crujeiras-Pérez, B.; Jiménez-Aleixandre, M.P. High school students' engagement in planning investigations: Findings from a longitudinal study in Spain. Chem. Educ. Res. Pract. 2017, 18, 99-112. [CrossRef]

10. Eldokhny, A.A.; Drwish, A.M. Effectiveness of Augmented Reality in Online Distance Learning at the Time of the COVID-19 Pandemic. Int. J. Emerg. Technol. Learn. 2021, 16, 9. [CrossRef] 
11. Chang, X.-Q.; Zhang, D.-H.; Jin, X.-X. Application of Virtual Reality Technology in Distance Learning. Int. J. Emerg. Technol. Learn. 2016, 11, 76-79. Available online: https:// online-journals.org/index.php/i-jet/article/view/6257 (accessed on 5 October 2021). [CrossRef]

12. William, V.-C.; Milton, R.-C. and Xavier, P.-P. Improvement of an Online Education Model with the Integration of Machine Learning and Data Analysis in an LMS. Appl. Sci. 2020, 10, 5371.

13. Izhar, N.A.; Na, Y.M.A.; Na, K.S. Teaching in the Time of Covid-19: The Challenges Faced By Teachers in Initiating Online Class Sessions. Int. J. Acad. Res. Bus. Soc. Sci. 2021, 11, 1294-1306.

14. Rosalina, E.; Nasrullah, N.; Elyani, E. Teacher's Challenges towards Online Learning in Pandemic Era. LET: Linguistics. Lit. Engl. Teach. J. 2020, 10, 71-88.

15. Mccaslin, S.; Brown, F. Case Study: Challenges and Issues in Teaching Fully Online Mechanical Engineering Courses; Springer: Cham, Switzerland, 2015.

16. Asgari, S.; Trajkovic, J.; Rahmani, M.; Zhang, W.; Lo, R.C.; Sciortino, A. An observational study of engineering online education during the COVID-19 pandemic. PLoS ONE 2021, 16, e0250041. [CrossRef] [PubMed]

17. Cho, H.J.; Zhao, K.; Lee, C.R.; Runshe, D.; Krousgrill, C. Active learning through flipped classroom in mechanical engineering: Improving students' perception of learning and performance. Int. J. STEM Educ. 2021, 8, 1-13. [CrossRef] [PubMed]

18. Alkhatib, O.J. An interactive and blended learning model for engineering education. J. Comput. Educ. 2018, 5, 19-48. [CrossRef]

19. Si, S.; Cai, Z.; Zhang, S.; Sun, S.; Wang, J.-Q. Hybrid Learning Mode for Industrial Engineering Specialized Courses in China; Springer: Berlin, Germany, 2010; pp. 316-325. [CrossRef]

20. Jamison, A.; Kolmos, A.; Holgaard, J. Hybrid Learning: An Integrative Approach to Engineering Education. J. Eng. Educ. 2014, 103, 253-273. [CrossRef] 